\title{
Spontaneous spinal epidural haematoma: management and main risk factors in era of anticoagulant/antiplatelet treatment
}

\author{
Ivana Stetkarova $^{1}\left(\mathbb{D}\right.$, Edvard Ehler $^{2}$, Karel Brabec ${ }^{1}$, Lenka Jelinkova ${ }^{1},{\text { Miroslava } \text { Chylova }^{1} \text {, Jiri Weichet }}^{3}$, \\ Leos Ungermann ${ }^{4}$, Tomas Peisker ${ }^{1}$ \\ ${ }^{1}$ Department of Neurology, Third Faculty of Medicine, Charles University and Faculty Hospital Kralovske Vinohrady, Czech Republic \\ ${ }^{2}$ Neurological Department, Faculty of Health Studies, Pardubice University and Pardubice Regional Hospital, Czech Republic \\ ${ }^{3}$ Department of Radiology, Third Faculty of Medicine, Charles University and Faculty Hospital Kralovske Vinohrady, Czech Republic \\ ${ }^{4}$ Department of Radiology, Faculty of Health Studies, Pardubice University and Pardubice Regional Hospital, Czech Republic
}

\begin{abstract}
Aim of the study. Spontaneous spinal epidural haematomas (SSEH) are rare nosological units wherein acute collections of blood develop in the spinal canal. SSEH are usually manifested by sudden severe back pain accompanied by the development of neurological symptoms. In this study, we retrospectively describe management and the main risk factors of SSEH in a series of 14 cases.

Material and methods. Between 2010 and 2019, we examined 14 patients (age range 17-89 years, 10 women) diagnosed with SSEH. Eight cases were patients using anticoagulant therapies (six warfarin, one dabigatran, one apixaban) and two others were using ASA of $100 \mathrm{mg} /$ day. The exact localisation and extent of changes was determined from acute magnetic resonance imaging. Three people using warfarin had INR values higher than 3.0 at the time of their diagnosis.

Results. Ten patients (71\%) were taking oral anticoagulants or antiplatelet agents. In seven patients, SSEH were localised in the lower cervical/thoracic spine. Ten patients (71\%) had arterial hypertension. Six patients underwent acute surgery due to rapidly developing spinal cord compression. Eight patients (57\%) with slight or mild neurological symptoms were successfully managed without surgery.

Conclusions. SSEH should be suspected in any patient receiving anticoagulant/antiplatelet agents who complains of sudden, severe back pain accompanied by neurological symptoms. SSEH is mostly localised in the lower cervical/thoracic spine. Arterial hypertension appears to be a risk factor of SSEH. Early decompression is an important therapeutic approach; in cases with minor neurological deficits, conservative treatment may be chosen.
\end{abstract}

Key words: spontaneous spinal epidural haematoma, spinal cord compression, anticoagulant therapy, surgical and non-surgical management, warfarin

(Neurol Neurochir Pol 2021; 55 (6): 574-581)

\section{Introduction}

Spontaneous spinal epidural haematomas (SSEH) are rare nosological units concerning the expansion of blood collection in the spinal canal without clear traumatic or iatrogenic causes [1]. The incidence of SSEH is usually reported as $0.1 / 100,000$ inhabitants $[2,3]$ and the male-to-female ratio is 1.4:1 [4]. Spontaneous spinal epidural haematomas cases have been detected more frequently with the wider availability of magnetic resonance imaging (MRI), which is the most important morphological method for SSEH detection [5].

Address for correspondence: Ivana Stetkarova, Head of Department of Neurology, Third Faculty of Medicine, Charles University of Prague, Ruska 87 Str. Prague 10, Czech Republic; e-mail: ivana.stetkarova@fnkv.cz

Received: 21.01.2021 Accepted: 25.05.2021 Early publication date: 12.10.2021

This article is available in open access under Creative Common Attribution-Non-Commercial-No Derivatives 4.0 International (CC BY-NC-ND 4.0) license, allowing to download articles and share them with others as long as they credit the authors and the publisher, but without permission to change them in any way or use them commercially. 
Anticoagulation and antiplatelet therapy are the commonest management option in various indications, especially in elderly patients. One important and rare complication of this therapy is SSEH [6-8]. This acute condition requires rapid diagnostics and therapeutic intervention. Surgical treatment remains the gold standard, especially in cases of progressive neurological deficit [9]. In minor haematomas associated with only slight neurological symptoms, it is possible to choose conservative management with detailed monitoring of neurological functions [7-10].

To date, SSEH has not been extensively studied in as large a population of patients as is presented in this study. We retrospectively studied a group of 14 patients who were diagnosed and treated in two hospitals between 2010 and 2019. We discuss the clinical symptoms of SSEH, diagnostic procedures, conservative and surgical treatments, and different risk factors.

\section{Material and methods}

Between 2010 and 2019, 14 patients (aged 17-89 years, 10 women) were hospitalised with spinal epidural haematomas in two large hospitals in the Czech Republic. Patients were taken from the database of the Departments of Neurology at University Hospital in Prague and University Hospital in Pardubice. Both these hospitals are public ones providing care to a local district with a population of more than 1 million inhabitants. Data was analysed from patients' medical histories and clinical reports from the intensive care unit, surgical and neurological departments. We analysed demographic data, risk factors with stress on anticoagulant/antiplatelet treatment, clinical and MRI findings, treatment approach, and clinical outcomes. Only such patients were included in this study who fulfilled the criteria of SSEH: no history of recent trauma, clinical picture of spinal lesion, and spinal MRI without evidence of bleeding source. If patients presented haematomas related to any type of trauma (mild, severe, iatrogenic, or therapy-connected), their data was not analysed. The Ethical Committees for both hospitals approved this retrospective study (EK-E/02/0/2020).

A common MRI protocol for spinal imaging was used in both hospitals, including T1 weighted, T2 weighted and fat suppressed T2 weighted sagittal sequences; T2 weighted or gradient $\mathrm{T} 2{ }^{*}$ weighted axial sequences.

Apart from a detailed clinical neurological examination, we assessed the severity of spinal cord disability using the American Spinal Injury Association Impairment Scale (AIS) classification, where A corresponds to a complete spinal lesion and $\mathrm{E}$ is a normal finding [11]. AIS classification was extracted from components of the chart given at the beginning of the patient's complaints after the hospital admission.

\section{Results}

Table 1 sets out the demographic and clinical data, including MRI showing haematoma localisation, treatment efficacy, and risk factors with a focus on anticoagulant use.
Fourteen patients aged 17-89 years (median 67.5) with SSEH were finally included in this retrospective study. Most were older and aged 59-69 years (eight subjects, 57\%), while two patients were young (17 and 42 years). Women accounted for $71 \%$ of the patients. The most frequent comorbidities were cardiovascular diseases (hypertension, atrial fibrillation, atherosclerosis, and deep vein thrombosis). Ten patients aged above 59 years suffered from arterial hypertension (71\%). Six of them $(60 \%)$ were treated by a combination of three antihypertensive drugs. Eight patients were taking oral anticoagulant therapy (six warfarin, one dabigatran, and one apixaban) and two patients were using ASA of $100 \mathrm{mg} /$ day. In summary, 10 patients out of 14 (71\%) were given oral anticoagulant/ /antiplatelet therapy. There was an increase of INR values above 3.0 in three patients using warfarin (two cases for atrial fibrillation, one for deep vein thrombosis). One of them (patient 5) had a history of the Valsalva manoeuvre having been performed in close proximity to the onset of the problems. One young patient was pregnant (week $36+6$ days), and suffering from iron deficiency anaemia. Atrial fibrillation was present in six patients $(46 \%)$, dyslipidaemia in three $(21 \%)$, obesity (BMI above 30 ) in three (21\%), deep vein thrombosis in two (14\%), anaemia in two (14\%), diabetes mellitus in one (7\%), smoking in one (7\%), rheumatoid arthritis in one (7\%), and hypothyroidism in one $(7 \%)$. Ten patients $(71 \%)$ had two or more vascular risk factors. In addition, spondylogenic spinal stenosis was present in two patients, and two patients had old osteoporotic fractures at the level of SSEH.

All patients in this study reported acute onset of severe pain as the initial symptom, mostly in the lower cervical spine (eight subjects, 57\%). Twelve patients reported some degree of neurological deficit accompanying the pain. Two patients (5 and 6) experienced urinary retention at the beginning of SSEH. Only two patients ( 3 and 7 ) did not develop any neurological deficit. The median time between clinical symptom onset and acute neurological assessment in a hospital was 4.5 hours (2-22 hours).

All patients underwent urgent magnetic resonance imaging for the detection of SSEH. The time interval between symptom onset and spinal cord MRI ranged from 5 to 26 hours, with a median of 12.5 hours. With respect to the affected level of the spine, the lower cervical/upper thoracic region was the most common site of involvement (seven subjects, 50\%). Three patients had localisation in the middle thoracic spine, and four patients in the lower thoracic/upper lumbar level. Nine of our patients (64\%) had SSEH in the posterior (dorsal) epidural space, four patients at the anterior (ventral) epidural space, and one had a combination of both.

Six patients (43\%) underwent surgery (decompression, bilateral laminectomy) due to rapidly developing spinal cord compression (Fig. 1-3). The time interval between symptom onset and operation ranged from 7 to 28 hours, with a median of 16.5 hours. Before the surgery, frozen plasma was used in one patient (patient 10) to normalise INR. One patient (patient 13) 


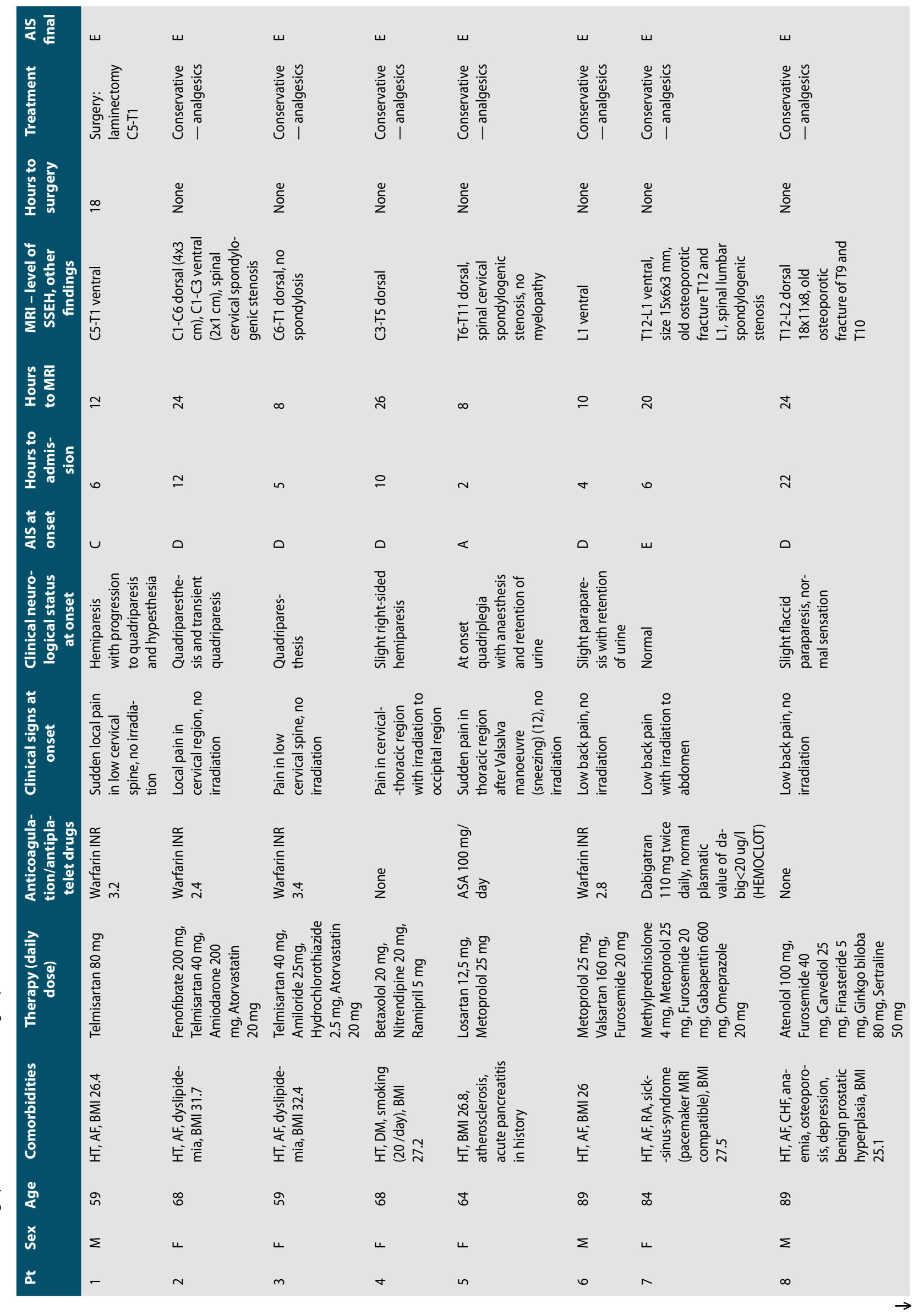




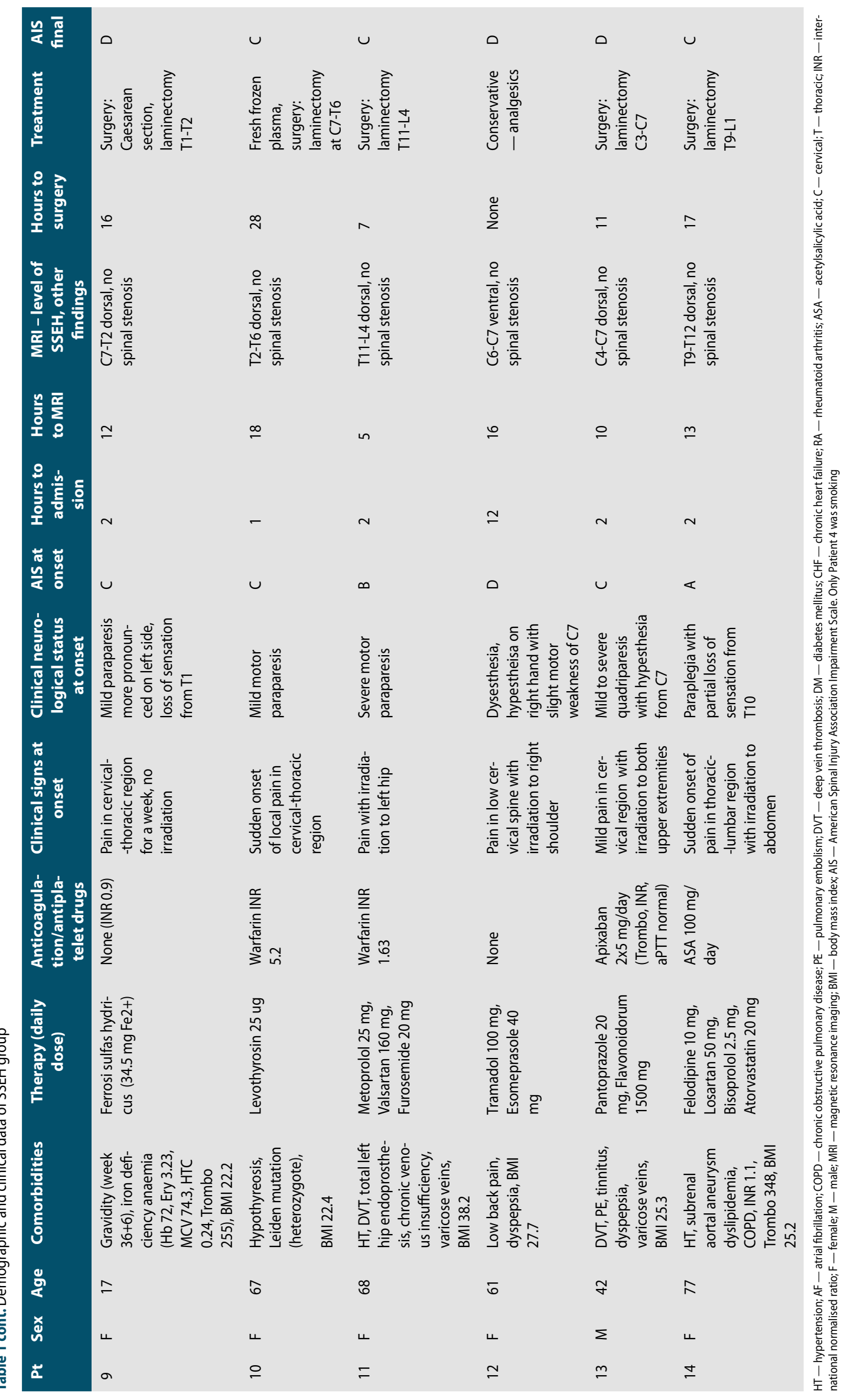




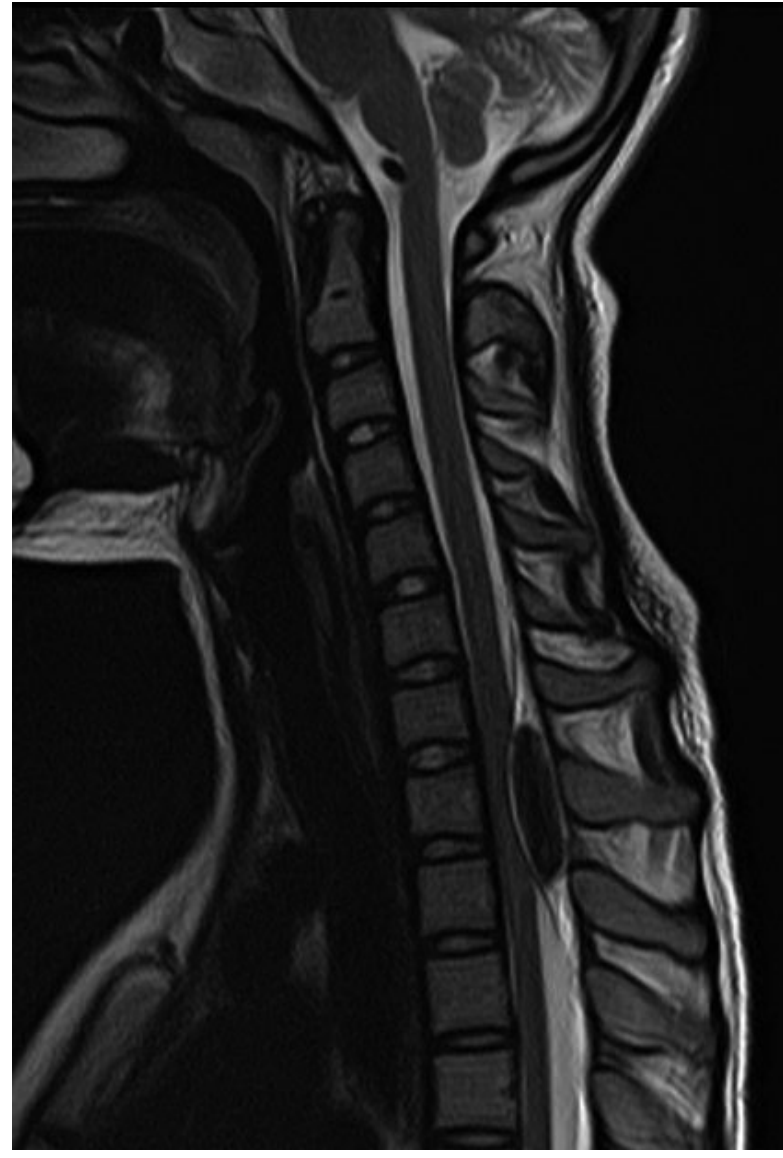

Figure 1. MRI of cervical/thoracic spine (sagittal T2W) performed after onset of symptoms shows expansive behaviour of extradural non-homogenic mass in posterior epidural space (patient 9)

taking apixaban had normal coagulation in the blood. Patient 7 presented a normal plasmatic value of dabigatran in the blood (dabigatran was $<20 \mathrm{ug} / \mathrm{l}$, proved by HEMOCLOT - trombin inhibitory assay). In three patients after surgical decompression, the clinical condition improved substantially. The clinical conditions of the other eight patients (57\%) were more favourable and conservative approaches (symptomatic treatment with analgesics) along with detailed monitoring of neurological functions were chosen. Ten patients showed clinical improvement by more than one point on AIS classification. No patient developed clinical worsening. All patients underwent rehabilitation. Nine patients were able to walk without assistive devices (Patients 1-6, 9, 12,13). One female patient (Patient 5) suffered from very severe neurological deficit (AIS A) at disease onset. This spontaneously improved very quickly and she refused surgery. She had a full clinical recovery within 24 hours. This case has already been published [12].

\section{Discussion}

Spontaneous spinal epidural haematoma (SSEH) is a rare entity, with the prognosis affected by the severity of spinal

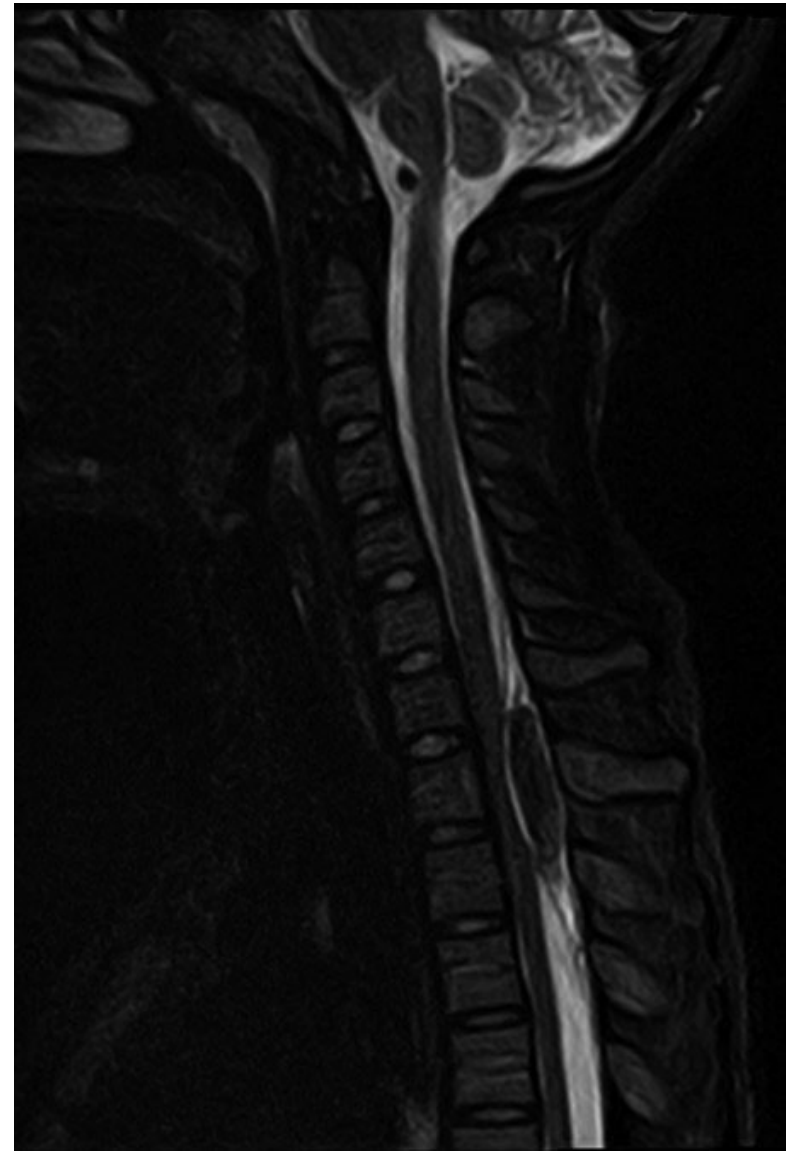

Figure 2. MRI of cervical/thoracic spine (sagittal STIR) shows same extradural mass localised dorsally with compression of spinal cord but without myelopathy (patient 9 )

cord compression, a delayed final diagnosis, prompt surgical intervention, and a well-chosen conservative approach in spontaneously improving cases $[8,13]$. In our study, one of the most important findings was that $71 \%$ of patients (mostly of older age) received oral anticoagulation/antiplatelet treatment and $57 \%$ of patients with slight or mild neurological symptoms were successfully treated with a conservative approach.

The cause of SSEH is usually a vessel rupture but the pathophysiology is not yet fully understood. The exact localisation of rupture and source of bleeding during surgery is mostly not identified [14]. Another important source of bleeding is the venous plexus in the epidural space $[2,3]$. The reported cause of SSEH is a sharp increase in intra-abdominal or intra-thoracic pressure which is then transferred to the spinal vessels $[12,15]$.

The incidence of SSEH is bimodal in age and location. The age structure of SSEH patients has its first peaks between the ages of 15 and 20 and again between 67 and 70 [16, 17]; however, in our patient group most people were aged 59-69 years (eight subjects). The peaks of the location curve are the spinal levels of C6 and T12 [18]. In this study, the lower cervical/upper thoracic region was the most common site of 


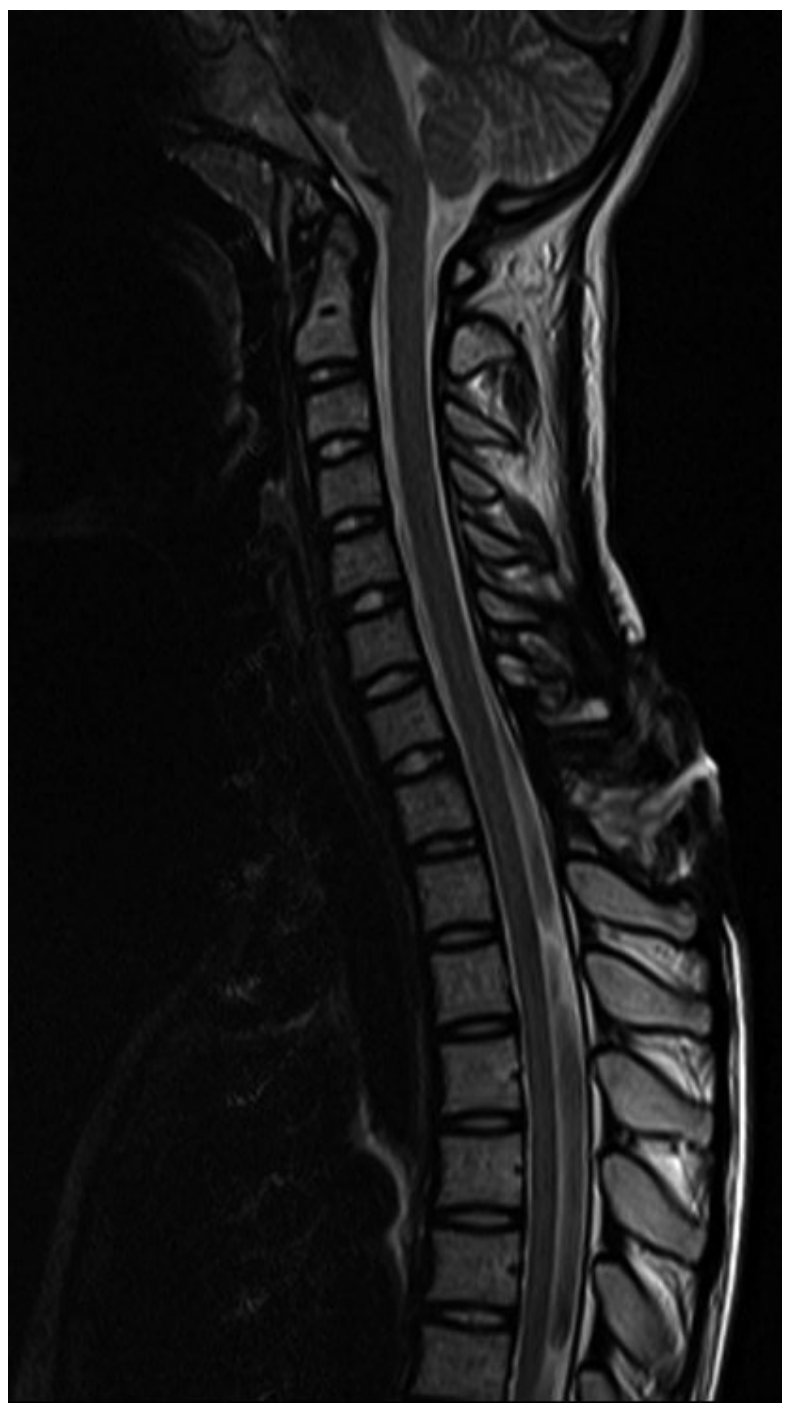

Figure 3. MRI of cervical/thoracic spine (sagittal T2W) performed after successful decompressive surgery with total removal of haematoma (12 days after onset of SSEH), showing only oedematous changes in posterior epidural space (patient 9)

involvement, followed by the lower thoracic/upper lumbar level. The posterior (dorsal) epidural space is affected most commonly due to its position relative to the spinal sac [3]. We observed similar findings where most of our patients (64\%) had SSEH in the posterior epidural space.

The main risk factor for the development of SSEH is a coagulation disorder, either congenital (e.g. haemophilia) or iatrogenically induced (e.g. anticoagulation, antiplatelet therapy, haemodialysis) $[13,15,19]$. Anticoagulant therapy is used in thromboembolic diseases (acute phlebothrombosis and pulmonary embolism), in the treatment of atrial fibrillation, in pregnant women, in dialysis patients, and for many other indications. SSEH as a complication of anticoagulation treatment most often develops with the use of warfarin [20, 21], especially in patients who have an INR of above 3 [13]. There have been reports of patients with SSEH on direct oral anticoagulants (DOAC) such as dabigatran [22, 23], rivaroxaban [24, 25] and apixaban [26], but much less than in warfarin. Similar observations of SSEH development in patients with warfarin, dabigatran and rivaroxaban were found also in our study.

Other SSEH risks include atherosclerosis and arterial hypertension [13, 27-29], pregnancy [19], and deep diving [30]. In a population aged 65 to 74 , the overall prevalence of hypertension was as high as $50 \%[31,32]$ which was in concordance with our data. Antihypertensive treatment using three drugs in an elderly population was observed in 30\% [31]. In contrast, we present a higher incidence (60\%) of these patients in our study. Two patients presented old porotic fractures in proximity to SSEH. Recently, three unusual cases of spinal epidural haematoma occurred in senile patients affected by osteoporotic fractures [33].

The first clinical manifestation of SSEH is usually a sudden, sharp pain in the back accompanied immediately or after a slight delay by neurological symptoms caused by the compression of tissue structures located in the spinal canal [13, 24]. An early symptom of a growing haematoma is sometimes described as a stabbing, severe pain in the spine $[16,34]$. Other neurological symptoms may gradually develop depending on the location of the haematoma - transverse spinal cord lesions, spinal cord hemisection, posterior spinal cord syndrome, conus medullaris and epiconus syndrome, cauda equina syndrome, different radicular syndromes, etc. [13]. The course of patients in our cohort corresponded to the above description but with varying severities and durations of disability. The hemiparesis in one patient progressed to quadruparesis; another patient reported subjective weakness of all limbs, which improved during her transport to the hospital via ambulance. Two patients experienced urinary retention at the beginning.

Magnetic resonance imaging of the spinal canal is the most important method in the diagnosis of SSEH: the haematoma appears as an expansive lesion; its signal changes over time mainly due to haemoglobin degradation, and fluid movement in the spinal canal can also cause actual changes of the haematoma's appearance. In the initial phase, an acute haematoma is isosignal in T1 weighted scans and hypersignal in T2 weighted scans. In the following days, the haematoma signal intensity can alternate in both sequences, but it typically increases in T1 weighted scans during days 3-5 [35]. Afterwards, in chronic haematoma, both $\mathrm{T} 1$ and $\mathrm{T} 2$ signal decrease due to haemosiderin formation. Loss of signal in $\mathrm{T} 2{ }^{\star}$ gradient sequence helps to differentiate haematoma from other expansive lesions; this phenomenon is caused by the presence of deoxyhaemoglobin and hemosiderin in acute and chronic haematoma, respectively [36]. The baseline MRI can also show spinal cord oedema or myelopathy; its presence is considered to be an unfavourable prognostic factor.

The treatment of SSEH depends on the severity and dynamics of the neurological symptoms [37]. Surgical management is indicated in patients with spinal cord involvement 
according to the AIS scale A-C [11]; however, recently, we published a case report of SSEH after loud sneezing in a patient using antiplatelet therapy (100 mg ASA daily), where the initial paraplegia fully resolved spontaneously within 24 hours [12].

The mean length of SSEH with a conservative approach has been observed on MRI to be significantly longer compared to operated SSEH [17]. In this study, our results did not support this observation.

Due to the quick development of neurological symptoms, SSEH requires a multidisciplinary team and proper management, with 24/7 MRI availability and surgical decompression of the spinal cord. The prognosis of the patient depends on his/her level of disability before surgery and the speed of spinal cord decompression [13, 16, 34]. Surgery (usually laminectomy or hemilaminectomy) should be performed on incomplete lesions within 48 hours of the onset of symptoms $[28,38]$. In our group, spinal cord decompression was performed 7-28 hours after SSEH depending on the development of clinical symptoms, and no patient reported a worsening of neurological deficit.

Conservative SSEH management is based on the elimination of risk factors and minimising the risk of further bleeding. Immediate interruption of anticoagulant therapy is recommended in the overuse of warfarin. Correction of the coagulation is improved by the administration of fresh frozen plasma, vitamin $\mathrm{K}$ or prothrombin complex concentrate. Idarucizumab, a specific antidote to dabigatran, has been successfully used in SSEH, resulting in a complete neurological recovery [23]. Adnexanet alpha is recommended to be used as an antidote for patients taking apixaban or rivaroxaban [39]. In our study, we used fresh frozen plasma only in one patient with an INR of above 3 . Bed rest at the beginning and analgesic therapies are also recommended. Long-term monitoring of patients is necessary to detect the possible progression of the condition, thus enabling any indications of surgery early on.

\section{Clinical implications/future directions}

The commonest risk factors which can lead to SSEH are anticoagulant therapy (warfarin or direct oral anticoagulants) and intensively treated hypertension in triple combination. Other predisposing factors are antiplatelet therapy, anaemia, metabolic diseases (diabetes mellitus, hypothyroidism) and pregnancy.

SSEH is a rare disease but it should be considered in patients with acute spinal cord or radicular symptoms accompanied by a sudden sharp pain in the spine.

Approaches to treating SSEH must be individual, with careful monitoring of the patient's clinical condition and a responsible choice of treatment modalities, whether surgical or conservative. Severe neurological deficit at the beginning and/or rapid progression of the clinical neurological status are the most important observations leading to prompt surgical decompression of the spinal cord. We recommend being more conservative if moderate neurological deficit is present, especially in older people who have multiple chronic diseases, when the surgical approach may carry a higher risk.

Acknowledgments: Supported by Research Projects of Charles University PROGRES Q 35 and Q37.

Conflict of interest: The authors state no conflict of interest regarding the publication of this article.

\section{References}

1. Messerer M, Dubourg J, Diabira S, et al. Spinal epidural hematoma: not always an obvious diagnosis. Eur J Emerg Med. 2012; 19(1): 2-8, doi: 10.1097/MEJ.0b013e328346bfae, indexed in Pubmed: 22037566.

2. Sirin S, Arslan E, Yasar S, et al. Is spontaneous spinal epidural hematoma in elderly patients an emergency surgical case? Turk Neurosurg. 2010; 20(4): 557-560, doi: 10.5137/1019-5149.JTN.2338-09.1, indexed in Pubmed: 20963712.

3. Taniguchi LU, Pahl FH, Lúcio JED, et al. Complete motor recovery after acute paraparesis caused by spontaneous spinal epidural hematoma: case report. BMC Emerg Med. 2011; 11: 10, doi: 10.1186/1471227X-11-10, indexed in Pubmed: 21794133.

4. Lonjon MM, Paquis P, Chanalet S, et al. Nontraumatic spinal epidural hematoma: report of four cases and review of the literature. Neurosurgery. 1997; 41(2): 483-6; discussion 486, doi: 10.1097/00006123-199708000-00035, indexed in Pubmed: 9257319.

5. Baeesa S, Jarzem P, Mansi M, et al. Spontaneous Spinal Epidural Hematoma: Correlation of Timing of Surgical Decompression and MRI Findings with Functional Neurological Outcome. World Neurosurg. 2019; 122: e241-e247, doi: 10.1016/j.wneu.2018.09.224, indexed in Pubmed: 30336292.

6. Kirazli Y, Akkoc Y, Kanyilmaz S. Spinal epidural hematoma associated with oral anticoagulation therapy. Am J Phys Med Rehabil. 2004; 83(3): 220-223, doi: 10.1097/01.phm.0000107498.91919.44, indexed in Pubmed: 15043358.

7. Siasios ID, Vakharia K, Gibbons KJ, et al. Large, spontaneous spinal subdural-epidural hematoma after epidural anesthesia for caesarean section: Conservative management with excellent outcome. Surg Neurol Int. 2016; 7(Suppl 25): S664-S667, doi: 10.4103/21527806.191073, indexed in Pubmed: 27843682.

8. Eto F, Tatsumura M, Iwabuchi S, et al. Clinical features of spontaneous spinal epidural hematoma. J Rural Med. 2019; 14(2): 206-210, doi: 10.2185/jrm.3005, indexed in Pubmed: 31788143.

9. Kim T, Lee $\mathrm{CH}$, Hyun SJ, et al. Clinical Outcomes of Spontaneous Spinal Epidural Hematoma : A Comparative Study between Conservative and Surgical Treatment. J Korean Neurosurg Soc. 2012; 52(6): 523-527, doi: 10.3340/jkns.2012.52.6.523, indexed in Pubmed: 23346323.

10. Raasck K, Khoury J, Aoude A, et al. Nonsurgical management of an extensive spontaneous spinal epidural hematoma causing quadriplegia and respiratory distress in a choledocholithiasis patient: A case report. Medicine (Baltimore). 2017; 96(51): e9368, doi: 10.1097/ MD.0000000000009368, indexed in Pubmed: 29390530.

11. Marino RJ, Barros T, Biering-Sorensen F, et al. ASIA Neurological Standards Committee 2002. International standards for neurological classification of spinal cord injury. J Spinal Cord Med. 2003; 26 Suppl 
1: S50-S56, doi: 10.1080/10790268.2003.11754575, indexed in Pubmed: 16296564.

12. Štětkářová I, Jelínková L, Janík V, et al. Spontaneous spinal epidural hematoma after abrupt sneezing with prompt recovery of severe paraparesis. Am J Emerg Med. 2014; 32(12): 1555.e3-1555.e5, doi: 10.1016/j.ajem.2014.04.039, indexed in Pubmed: 24857250.

13. González AM, Cuello JP, Cruz PMR, et al. Spontaneous spinal epidural haematoma: A retrospective study of a series of 13 cases. Neurología (English Edition). 2015; 30(7): 393-400, doi: 10.1016/j. nrleng.2014.03.005.

14. Kirsch E, Gratzl O, Mindermann Th, et al. Coagulopathy Induced Spinal Intradural Extramedullary Haematoma: Report of Three Cases and Review of the Literature. Acta Neurochirurgica. 2001; 143(2): 135-140, doi: 10.1007/s007010170118.

15. Morandi X, Riffaud L, Chabert E, et al. Acute nontraumatic spinal subdural hematomas in three patients. Spine (Phila Pa 1976). 2001; 26(23): E547-E551, doi: 10.1097/00007632-20011201000022, indexed in Pubmed: 11725255.

16. Kreppel D, Antoniadis G, Seeling W. Spinal hematoma: a literature survey with meta-analysis of 613 patients. Neurosurg Rev. 2003; 26(1): 1-49, doi: 10.1007/s10143-002-0224-y, indexed in Pubmed: 12520314.

17. Groen RJM. Non-operative treatment of spontaneous spinal epidural hematomas: a review of the literature and a comparison with operative cases. Acta Neurochir (Wien). 2004; 146(2): 103-110, doi: 10.1007/s00701-003-0160-9, indexed in Pubmed: 14963742.

18. Zhang S, Geng F, Wang J, et al. Rapid Recovery of Spontaneous Spinal Epidural Hematoma without Surgical Treatment: Case Report and Literature Review. World Neurosurg. 2018; 115: 216-219, doi: 10.1016/j.wneu.2018.04.145, indexed in Pubmed: 29709757.

19. Boukobza M, Haddar D, Boissonet M, et al. Spinal subdural haematoma: a study of three cases. Clin Radiol. 2001; 56(6): 475-480, doi: $10.1053 /$ crad.2000.0466, indexed in Pubmed: 11428797.

20. Lederle FA, Cundy KV, Farinha P, et al. Spinal epidural hematoma associated with warfarin therapy. Am J Med. 1996; 100(2): 237-238, doi: 10.1016/s0002-9343(97)89465-x, indexed in Pubmed: 8629661.

21. Vayá A, Resurección M, Ricart JM, et al. Spontaneous cervical epidural hematoma associated with oral anticoagulant therapy. Clin Appl Thromb Hemost. 2001; 7(2): 166-168, doi: 10.1177/107602960100700215, indexed in Pubmed: 11292196.

22. Bamps $\mathrm{S}$, Decramer $\mathrm{T}$, Vandenbussche $\mathrm{N}$, et al. Dabigatran-associated spontaneous acute cervical epidural hematoma. World Neurosurg. 2015; 83(2): 257-258, doi: 10.1016/j.wneu.2014.10.012, indexed in Pubmed: 25463422.

23. Mathais Q, Esnault P, Cruc M, et al. Spontaneous Cervical Spinal Epidural Hematoma Associated with Dabigatran. World Neurosurg. 2018; 112: 264-266, doi: 10.1016/j.wneu.2018.01.199, indexed in Pubmed: 29425981.

24. Ismail R, Zaghrini E, Hitti E. Spontaneous Spinal Epidural Hematoma in a Patient on Rivaroxaban: Case Report and Literature Review. J Emerg Med. 2017; 53(4): 536-539, doi: 10.1016/j.jemermed.2017.06.005, indexed in Pubmed: 29079069.
25. Rahimizadeh A, Malekmohammadi Z, Williamson WL, et al. Rivaroxaban-induced acute cervical spine epidural hematoma: Report of a case and review. Surg Neurol Int. 2019; 10: 210, doi: 10.25259/ SNI_390_2019, indexed in Pubmed: 31768290.

26. Ardebol J, Cahueque M, Lopez W, et al. Spontaneous thoracic spinal subdural hematoma associated with apixaban therapy. J Surg Case Rep. 2019; 2019(4): rjz115, doi: 10.1093/jscr/rjz115, indexed in Pubmed: 31044059.

27. Nakanishi K, Nakano N, Uchiyama T, et al. Hemiparesis caused by cervical spontaneous spinal epidural hematoma: a report of 3 cases. Adv Orthop. 2011; 2011: 516382, doi: 10.4061/2011/516382, indexed in Pubmed: 21991415.

28. Baek BS, Hur JW, Kwon KiY, et al. Spontaneous spinal epidural hematoma. J Korean Neurosurg Soc. 2008; 44(1): 40-42, doi: 10.3340/ jkns.2008.44.1.40, indexed in Pubmed: 19096655.

29. Gelabert M, Iglesias M, González J, et al. Spontaneous spinal epidural hematomas: review of 8 cases. Neurologia. 2003; 18(7): 357-363, indexed in Pubmed: 14505243.

30. Hida K, Iwasaki Y, Akino M. Spontaneous spinal hemorrhage during scuba diving. Journal of Neurosurgery: Spine. 2002; 96(3): 351, doi: 10.3171/spi.2002.96.3.0351.

31. Burt VL, Whelton P, Roccella EJ, et al. Prevalence of hypertension in the US adult population. Results from the Third National Health and Nutrition Examination Survey, 1988-1991. Hypertension. 1995; 25(3): 305-313, doi: 10.1161/01.hyp.25.3.305, indexed in Pubmed: 7875754.

32. Cífková R, Skodová Z, Lánská V, et al. Prevalence, awareness, treatment, and control of hypertension in the Czech Republic. Results of two nationwide cross-sectional surveys in 1997/1998 and 2000/2001, Czech Post-MONICA Study. J Hum Hypertens. 2004; 18(8): 571-579, doi: 10.1038/sj.jhh.1001686, indexed in Pubmed: 15002000.

33. Figueroa J, DeVine JG. Spontaneous spinal epidural hematoma: literature review. J Spine Surg. 2017; 3(1): 58-63, doi: 10.21037/ jss. 2017.02.04, indexed in Pubmed: 28435919.

34. Chang FC, Lirng JF, Chen SS, et al. Teng, Chang CY. Contrast enhancement patterns of acute spinal epidural hematomas: A report of two cases. AJNR. 2003; 24: 366-369.

35. Holtås S, Heiling M, Lönntoft M. Spontaneous spinal epidural hematoma: findings at MR imaging and clinical correlation. Radiology. 1996; 199(2): 409-413, doi: 10.1148/radiology.199.2.8668786, indexed in Pubmed: 8668786.

36. Gopalkrishnan CV, Dhakoji A, Nair S. Spontaneous cervical epidural hematoma of idiopathic etiology: case report and review of literature. J Spinal Cord Med. 2012; 35(2): 113-117, doi: 10.1179/2045772312Y.0000000001, indexed in Pubmed: 22333537.

37. Fedor M, Kim ES, Ding K, et al. Spontaneous Spinal Epidural Hematoma: A Retrospective Study on Prognostic Factors and Review of the Literature. Korean J Spine. 2011; 8(4): 272-282, doi: 10.14245/ kjs.2011.8.4.272, indexed in Pubmed: 26064145.

38. Oh JYL, Lingaraj K, Rahmat R. Spontaneous spinal epidural haematoma associated with aspirin intake. Singapore Med J. 2008; 49(12): e353-e355, indexed in Pubmed: 19122933.

39. Brown CS, Scott RA, Sridharan M, et al. Real-world utilization of andexanet alfa. Am J Emerg Med. 2020; 38(4): 810-814, doi: 10.1016/j. ajem.2019.12.008, indexed in Pubmed: 31870672. 